\section{Smaller, but still controversial}

\section{Washington}

CHEAPER and split into smaller parts, this year's version of the Earth Observing System (EOS) of 1992 resembles its predecessors only in its ability to generate controversy. Although the US Congress may feel better about the cost, one-third lower than the original $\$ 16,000$ million, critics say that the current plan to launch a series of small- to medium-sized orbiters late in the decade puts expediency before science and is an invitation to delay.

The idea for EOS came not from the research community but from officials at the US National Aeronautics and Space Administration (NASA). When outsiders complained that it was just another megaengineering projects, NASA won support from the US Congress and much of the scientific community by making it the star of its eco-friendly Mission to Planet Earth programme.

But EOS remains suspect because of its origins. Last fall, Congress decided to trim NASA's sails and told the agency that the project could cost no more than $\$ 11,000$ million. That limit - and some less-than- subtle language in the appropriations bill - forced NASA to redesign EOS.

In December, then NASA administrator Richard Truly announced that the project would be redesigned as a series of smaller platforms and staggered launches. Those details were revealed in March in a submission to Congress. Instead of two large platforms, both huge satellites about the size of the Hubble Telescope, EOS now will consist of six smaller mission that will fly on intermediate-sized boosters like the tried-and-true Atlas IIAS series.

Although the original EOS programme was to focus on broad issues of global changes, including ozone depletion, Earth physics and stratospheric chemistry, the new version concentrates on climate change. There are only 17 instruments instead of the original 30 , with six deferred until the middle of the next decade at the earliest.

Most researchers have welcomed the move to smaller platforms. With the flawed Hubble telescope and the tragic Challenger space shuttle in mind, they point out that smaller platforms have less at stake if one

\title{
Russians want business, not charity
}

\section{Washington}

Russian scientists lack a great deal these days, but they have lost none of their pride. Despite having to cross 5,000 miles, the message from senior science policymakers came across loud and clear during a two-hour video conference last week with members of the science committee of the US House of Representatives: Russian science wants a handshake from the United States, not a handout.

"Russia has something to offer you. We're not an under-developed country", Boris Saltykov, minister of science, advanced education and technology policy, told Representative George Brown (Democrat, California), who chairs the science committee. "The assistance that we're seeking must be one of mutual benefit. Although it could help alleviate our economic hardship, it could also provide knowledge that you in the United States are now lacking."

The teleconference was the third in a series of televised discussions, and the first international linkage, between the House Committee on Science, Space, and Technology and the scientific community. The hearing featured Saltykov and four other prominent Russian science administrators: Yurii Osipov, president of the Russian Academy of Sciences; Andrei Gonchar, first vice president of the academy; Yevgeniy Velikhov, an academy vice president, director of the Kurchatov Institute and a leading figure in disarmament efforts; and Yurii Koptev, director of the Space Research Institute and salesman to the West of the fruits of the former Soviet space programme. The communications system performed flawlessly.

The Russian delegation acknowledged the serious problems facing all areas of science and said repeatedly that Western cooperation could help to keep laboratories intact. But the most serious consequence of a possible brain-drain, they said, is not the loss of existing talent but the fact that it may not leave enough people to teach the next generation of scientists.

Russian is having "tremendous problems" converting from a defence-oriented economy to a civilian one, Velikhov said. And his colleagues suggested that the wrenching cultural changes needed for Russian science to thrive in the post-Soviet era may pose the biggest barrier to success.

"Conversion is more that just factories", said Osipov. "We also have to convert people's way of thinking. Right now we have thousands of scientists from the academy who had been doing military work and now have nothing to do. They are no longer being supported by the academy, and nobody knows what they are going to do next."

Jeffrey Mervis part goes wrong and allow scientists to modify later missions to correct deficiencies. But they are less happy about the order of the missions, which some say is a result of convenience rather than a response to the most pressing climate change questions.

As EOS now stands, the first platform (scheduled for 1998) will be a mediumsized satellite known as EOS-AM. Its Sunsynchronous orbit will keep it in perpetual morning, where it can observe the Earth when cloud cover is at a minimum. That platform will be followed by two smaller missions that will look at oceanic biomass and atmospheric aerosols. Two years later comes EOS-PM, another medium-sized probe that will observe the Earth in the afternoon, a time best suited for meteorological forecasting.

NASA argues that EOS-AM should fly first because scientists are most in need of the data from its instruments, including an infrared surface imager known as ASTER. (NASA gives models of earth biology a score of two on a scale of ten.). No one argues with that characterization, but there is concern as to whether EOS-AM will be able to answer any important questions soon.

"The ecologists don't know anything about their models," says one researcher. "You dump all this data on them and they won't know what to do with it."

Meanwhile, the answer to the question that all the policy-makers have been waiting for - is global warming happening, and if so, how fast? - seems likely to have to wait until the next century. That's when EOS-PM, which looks at atmospheric dynamics and global moisture, will start sending back data.

Researchers blame politics and tight funding for the apparently skewed priorities. EOS-AM benefits from the fact that ASTER is being built and paid for by the Japanese and is likely to be ready on time. (In fact, NASA was able to move the first EOS launch date forward by six months by going with EOS-AM.) At a time when NASA cannot afford delays or cost overruns, the benefits of an on-time, lowcost start to EOS are considerable.

"If you're going to launch just one, I'd say EOS-PM", says Dennis Hartmann, a University of Washington atmospheric researcher and chair of the EOS investigator's atmospheric panel. "But when you look at the practical realities — budget and schedule - you're drawn towards AM."

Accompanying the debate over the proper order is fear that the growing US deficit will stretch out the timetable for later missions. One congressional aide warns that EOS-AM could be the only mission launched in the next ten years. With EOS-PM and its compatriots stuck on the ground, such a delay could leave everybody but the ecologists up in the air.

Christopher Anderson 